\title{
Conversion of organic wastes to electricity in Nigeria: legal perspective on the challenges and prospects
}

\author{
O. J. Olujobi ${ }^{1}$ D. E. Ufua ${ }^{2} \cdot$ M. Olokundun ${ }^{1} \cdot$ O. M. Olujobi ${ }^{3}$
}

Received: 31 July 2020 / Revised: 21 September 2020 / Accepted: 4 December 2020 / Published online: 2 January 2021

(c) The Author(s) 2021

\begin{abstract}
This study explores the need for conversion of wastes to energy for a sustainable power sector and environmental development in Nigeria, to decrease greenhouse gas emissions and to offer incentives for investments in renewable energy sources, and to mitigate the concerns on disposal of hazardous wastes in the country. The study adopts a library-based doctrinal legal research technique with a conceptual approach, relying on existing literature. It explores the potency of existing laws and other legal provisions binding on the practice of waste management to power in Nigeria. Also, it carries out a comparative appraisal of the renewable system through organic wastes to electricity in other countries. The key finding of the study is that if practical measures are taken by the Nigerian government to control waste disposal, it will minimise wastes from the various sources in conformity with the legal and regulatory requirements and this can be utilised to generate electricity. The study proposes a model for converting wastes to electricity to sustain the ever-intensifying demands for energy and to combat ecological issues in Nigeria. The research concludes with recommendations for the fusion of regulations and non-regulatory incentives for conversion of wastes to electricity in Nigeria's power sector and advocates coherent legal framework on sources of energy with stringent enforcement of energy laws for stable electricity generation and sustainability in Nigeria's power sector.
\end{abstract}

Keywords Biomass energy $\cdot$ Electricity $\cdot$ Environment $\cdot$ Waste conversion $\cdot$ Waste disposal $\cdot$ Waste generation

JEL Classification Q4 $\mathrm{Q} 5 \cdot \mathrm{K} 32 \cdot \mathrm{K} 12 \cdot \mathrm{K} 2 \cdot \mathrm{P} 28 \cdot \mathrm{K} 42$

$\begin{array}{ll}\text { Abbreviations } \\ \text { MW } & \text { Megawatts } \\ \text { MJ/KG } & \text { Megajoules per kilogram } \\ \text { NERC } & \text { Nigerian Electricity Regulatory Commission } \\ \text { EPSR } & \text { Electric Power Sector Reform } \\ \text { TWh } & \text { Terawatt-hour } \\ \text { Mtoe } & \begin{array}{l}\text { A unit of energy used to describe the energy } \\ \text { content of all fuels, typically on an enormous } \\ \text { scale }\end{array}\end{array}$

Editorial responsibility: Mohamed F. Yassin.

O. J. Olujobi

olusola.olujobi@covenantuniversity.edu.ng

1 Department of Business Management, Covenant University, Ota, Ogun State, Nigeria

2 Department of Business Management, Centre for Economic Policy and Development Research (CEPDeR), Covenant University, Ota, Ogun State, Nigeria

3 Department of Economics, University of Lagos, Akoka, Nigeria

\section{Introduction}

The world is shifting towards low carbon energy through the conversion of wastes to useful resource for man's use ( $\mathrm{Li}$ et al. 2020). However, it seems that Nigeria has not taken advantage of her endowed renewable energy resources to generate electricity to solve the problem of an ongoing power outage in the country (Oke 2016). This deficit of stable electricity in Nigeria has impeded the nation's economic growth (Aderoju et al. 2017). Nigeria generates approximately $4000 \mathrm{MW}$ of electricity which is not adequate for its populace of over 206.14 million energy demands. Equally, the need to meet the rising demands justifies the adoption of other alternatives such as the conversion of wastes to energy to address power supply shortage in the economy (Okeniyi et al. 2012; Akinyemi et al. 2019a, b).

As the legal regime under the Electric Power Sector Reform Act, 2005, introduced, the Power Holding Company of Nigeria which was unbundled into 18 electrical firms as part of the reform processes in the sector but this has not crystallised to stable electricity supply in the country as 
over $50 \%$ of Nigeria's population still lacks stable electricity (Oke 2016). This justifies the premium put into the current research, to explore the values embedded in the conversion of waste to energy.

The current research sought to provide the legal and regulatory framework on renewable energy and conversion of wastes to electricity. The research takes a look at the prospects of wastes to electricity in Nigeria's power sector, challenges of conversion of wastes to energy in Nigeria power sector. The article also took a cursory look at the overview of the global policies on biomass energy utilisation, and lessons Nigeria can replicate in the conversion of wastes to electricity from some advanced countries, bioenergy strategies in the UK, bioenergy and allied policies in Italy, Netherlands and Sri Lanka. The study then presented a discussion of findings and a concluding section suggesting a few salient recommendations.

\section{Materials and methods}

This prompted this study for the conversion of wastes to energy, a policy that has been embraced by several countries in the world to promote electricity security and sufficiency (Jiang et al. 2012). The study explores extant literature to unpack the trends of waste management practices, the challenge of power supply and the use of organic waste to generate energy in Nigeria. The research relies on relevant literature from internet sources, a comprehensive appraisal of academic writing and analysis of significant statutory provisions with comparative analysis of the conversion of wastes to energy in the UK, Italy, Netherlands and Sri Lanka among others. This is aimed to project learning on the current trends on the practice of conversion of waste to energy, and possibly suggest a suitable approach on how to replicate it in the Nigerian power sector. The study also adopts secondary sources, such as bulletins, textbooks and primary sources. Other sources such as judicial authority reports and some unstructured consultations with some electricity consumers and regulatory bodies in the power sector were considered. This is to gain valuable knowledge, to propose reform and to suggest the need to use the lessons learnt from the literature in the research process. It is also to promote energy security and stable electricity supply in Nigeria.

\section{Results and discussion}

The key finding of the study is that if practical measures are taken by the Nigerian government to control waste disposal, it will minimise wastes from the various sources in conformity with the legal and regulatory requirements and this can be utilised to generate electricity. The study proposes a model for converting wastes to electricity to sustain the everintensifying demands for energy and to combat ecological issues in Nigeria.

It is apparent that Nigeria, as a nation, has abundant wastes to be converted to power to generate electricity to combat ongoing electric power outage in the country. Still, little or nothing has been done in this regard due to overdependence on hydroelectric and thermal energy sources. This trend was emphasised by Akhator et al. (2016), who noted that conversion of wastes to energy technology is still at infancy stage in Nigeria's power sector, compared to other countries where it has been utilised to generate heat and electricity in commercial quantity for the benefits of their citizens.

Conversion of wastes to electricity will improve electricity supply in Nigeria as the demands for electricity supply in the country is more than the current $4000 \mathrm{MW}$ in the national grid. This aligns with the notion of Oniemola and Sanusi (2007) stressing that renewable energy benefits are more than its environmental and social impacts which in this stead is essential for generating an adequate supply of electricity.

The privatisation and commercialisation of the Nigerian power sector have low impacts in promoting efficiency in the sector due to poor maintenance of electrical equipment. Oke (2013) had earlier emphasised that electricity supply in Nigeria relied significantly on hydropower, which has resulted in frequent outages of electricity due to underinvestment in other sources of energy. This was stressed by Oke (2016) stating that in Nigeria, constant electricity supply remains a problem, despite the huge capital investment in the sector.

Electricity generation from waste is sustainable as long as the appropriate technology is utilised. On the issue and concerns of appropriate technology (Akhator et al. 2016) noted that conversion of wastes to energy technology is still at infancy stage in Nigeria's power sector compared to other countries where it has been utilised to generate heat and electricity in commercial quantity for the benefits of their citizens.

The advantages of wastes to energy are a quantum such as a decline in wastes generation, cleanliness and decontamination, energy efficiency and stability in the power sector. These benefits were also summarised by Ibrahim (2002); and Sharmina et al. (2012) describing organic wastes as defective materials or materials made in the course of manufacture and utilisation of goods, especially those that are traceable by-products from plants and animals.

The current research sought to provide the legal and regulatory framework on renewable energy and conversion of wastes to electricity. To this end, the following are considered pertinent to the subject matter. 
To intensify biomass impact as a renewable energy basis, decrease greenhouse gas emission and enhance ecological countryside growth. For biomass to be sustained, the following yardsticks must be met: Stakeholders such as the waste manufacturers, monitors, lawmakers, professionals, procedure and equipment merchants, educationalists, mass media and the citizens must be engrossed in domestic waste administration strategies and procedures (Ufua et al. 2019). This is essential for efficient domestic waste management guidelines and approaches by incorporating the obligations of all stakeholders in making wastes control efficient in Nigeria. Legislation at the national level mainly offers the essential legal framework for waste management (Olujobi and Olusola-Olujobi 2020) These legislations and policies should border on the formation of institutions for underpinning environmental strategies and policies with more focused on environmental legislations (Ufua et al. 2020a).

Conversely, lack of funding hampers execution of these laws, which sometimes lack public participation which is a constraint to uniformity in the standard of waste management services. Also, there is a need for increased in budgetary allocations and human resources skills for waste management (Agboola 2011). There is the need for public acceptability of energy from wastes, as waste to power has many advantages it can render an economy. Recycling has many ecological benefits: it utilises less energy causing less pollution; it decreases the request for new resources; it reduces the quantity of waste landfilled. This necessitates the need for electricity to be provided efficiently without any detriment to the environment, the populace as uninterrupted power propels economic development and growth in a society. The concept of sustainable development includes the development of cleaner fuels and the need to improve the efficiency of energy use from the demand side.

There is the need for stringent legal framework on energy policy for sustainable economic growth which will set the nation on the firm ground of development for the interest of the present and future generations. Such procedure is expected to be technically efficient, economical and equitable in the sector (Fig. 1).

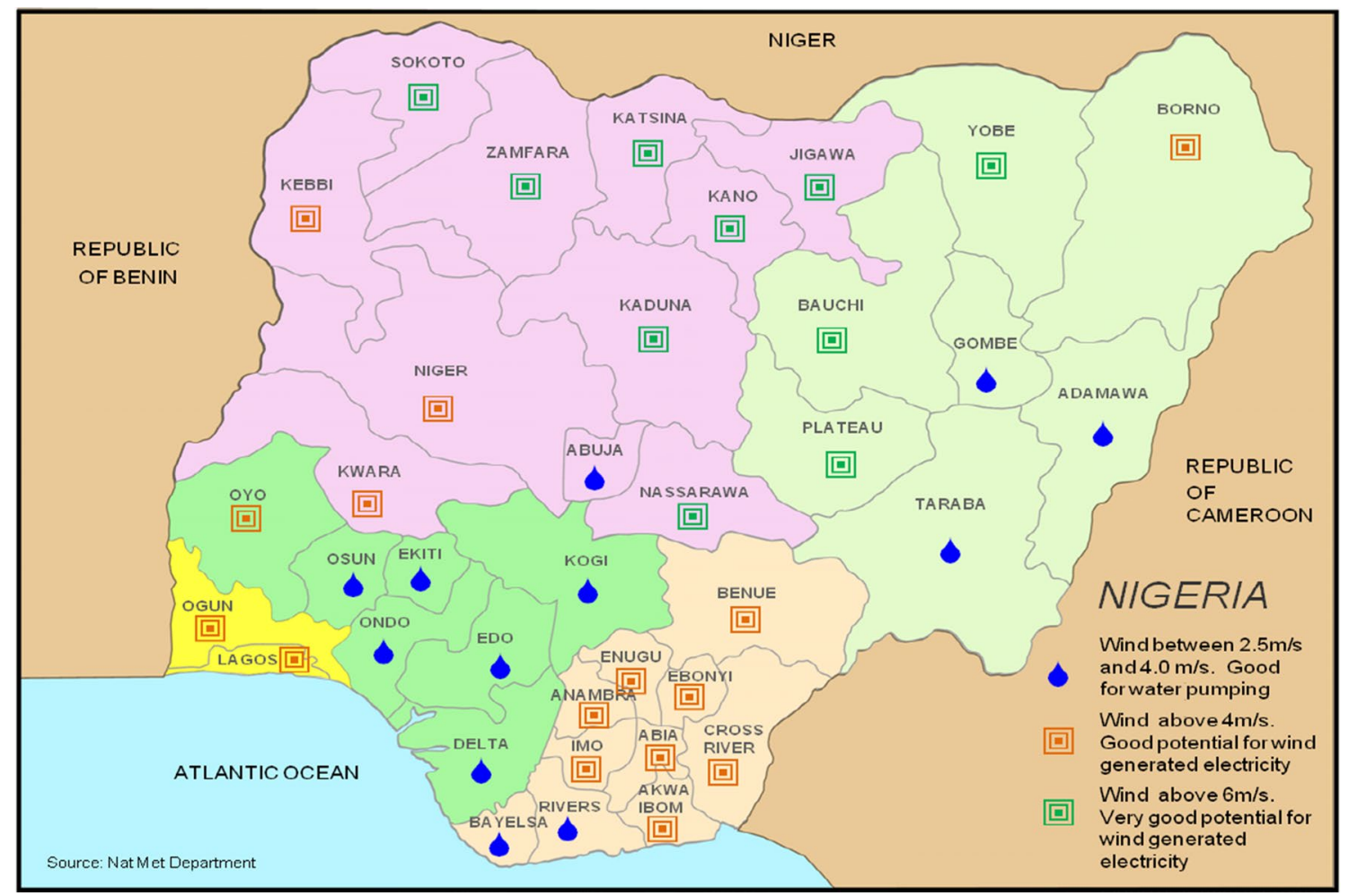

Fig. 1 Map of Nigeria exhibiting geographic allocation of renewable energy sources in the country. Source: https://www.googl e.com/search?tbs=simg:caqsyqejwkpuqnrznleavqelelcmpwgaygp gcamskmehxgffb78h1giza9ahzqfcb-ej-z-coec_18d6wofo_15j_1xpug _15t8amkaaevgpfyixjatw410zeo6zjju9zw xdqia94jjwinlkxhfxvb nns7ldu3da1uh02iaedasqjq7-cbokcggiariedvvnywwlej3twqkang oxcgvhdgxhc9qlipydcgoil20vmgnybmykgwoicgfyywxszwzapyj2a wskcs9tlzazmhpmbgw \&q=nigeria + wind + map\&tbm $=i s c h \& s a$ $=x \& v e d=2$ ahukewio_-mcz9trahwrmfwkhtiscyiqwg4 4 ahoecagqj $\mathrm{g} \& \mathrm{biw}=1366 \& \mathrm{bih}=657$ \#imgrc $=2 \mathrm{ug} 35 \mathrm{xdo} 7 \mathrm{bj} 3 \mathrm{um}$. (Accessed September 6, 2020) 


\section{The gap in the literature}

Most electricity generation in Nigeria come from the hydropower and thermal with minimal electrical energy produced from renewable energy bases. This is the primary source of electricity in Nigeria's power sector without considering renewable energy option with much energy potentials (Oyedepo 2012). The conventional energy sources tend to favour unified energy generation, which often steers to large-scale projects, substantial fiscal weight on Nigeria's economies and adverse ecological effects. The necessity for the decrease in greenhouse gas emissions may offer real encouragement to utilise other renewable energy sources such as the conversion of organic waste to electricity in Nigeria (Oke 2016; Egbetokun et al. 2018, 2020). A critical challenge facing the power sector in Nigeria is the absence of significant backing from the regulatory authorities in regulating the power sector. Another issue is the challenge with the development of competitive policies of electricity markets and to exercise their supervisory roles over the regulators, who are assigned to manage the sector to prevent abuse of discretionary powers by the officials on issues affecting electricity supply and generation in Nigeria (Olujobi and Olusola-Olujobi 2019).

Conversion of organic wastes to electricity is a viable option in Nigeria's power sector, better than other alternatives such as fossil fuel that tends to more expensive and not environmentally friendly (Okeniyi et al. 2012). Considering the volume of wastes generated in Nigeria through human undertakings and their toxic effects on the ecosystem and human health, triggered the need to embrace other technical schemes for safe discard of wastes, by converting it to electricity to end power outage for meaningful economic growth in the country (Olaleye and Fagbenle 2013). Studies have revealed that over $60-70 \%$ of the Nigerian masses does not have access to stable power (Oyedepo 2012). This problem may continue except if the Nigerian government expands its energy supply base and embrace wastes to energy know-how to decrease energy depletion and to save cost in the sector. Some of the significant problems with Nigeria's power sector are non-existence of precautionary and regular maintenance of electrical equipment. These have resulted in energy deficits and recurrent damage to electrical equipment due to vandalism and inadequate funding (Onyekwena et al. 2017). Lack of transparent billing system of energy consumption has occasioned illegal application of estimated billing system, due to lack of transparency (Oyewunmi and Olujobi 2016). These issues, coupled with the supply gaps in the sector, tended to have contributed to the inadequate development, which has resulted in incidences of the prolonged power outage in the country (Oyedepo 2012).
Moreover, it is also speculated that the determination of the Nigerian government to keep electricity price down, and cheap at the detriment of cost recovery. This has put the generation companies, transmission company of Nigeria and distribution companies in low revenues turn out, high operational debt profiles and inadequate electricity supply in the country (Onyekwena et al. 2017; Kopnina 2018). This observation tends to suggest the conflicting interest of the key stakeholder groups has also compounded the challenges further as the government on the hand, wishes to fulfil their policy, which the power generation companies struggle with operational cost challenges and the consistent incidences of failure demand (Seddon 2008; Ufua et al. 2020b).

\section{The relevance of cradle to cradle theory}

Cradle to cradle theory was propounded by McDonough and Braungart (2002). The theory emphasises the designing of intelligent products, processes and systems by considering the entire life cycle of the product, optimising material health, recyclability, renewable energy use, water efficiency and quality, and social responsibility (Ankrah et al. 2015). Cradle to cradle theory takes its inspiration from nature, in which all materials used can provide "nutrition" for nature or industry, maximise material value and safeguard ecosystems (Kopnina 2018). Cradle to cradle concept eliminates the concept of the waste. The purpose of the cradle to cradle Design is to restore continuous cycles of biological as well as technical nutrients with sustainable impacts on the environment and human health. The ideal cradle to cradle product is designed so that all of its materials are selected to cycle within either a biological or technical metabolism safely and to be reused or recovered at their highest possible value (Minkov et al. 2018). Material selection is an essential part of the development of a cradle to cradle product (Bach et al. 2018). A designer needs to understand the human and ecological health characteristics of the materials under consideration. The principles of cradle to cradle design can be applied to a different range of units and the entire city.

This work is anchored on the cradle to cradle theory. It is designed to stop the cycle of use-waste-pollute syndrome which suggests that certain products could be reused endlessly to make similar products (cradle to cradle), rather than recycled into lower-grade products until the last stop is a landfill (cradle to grave). This means that products can be used, recycled, and used again without losing any material quality-in cradle to cradle cycles. Therefore, the theory suggests that Nigeria can take advantage of her endowed renewable energy resources to generate electricity to solve the problem of the ongoing power outage in the country (Oke 2016). Furthermore, based on this theory there is an indication that Nigeria's abundance sunlight, hydro, biomass 
and wind among others sources of renewable energy which is available in the country can be harnessed in full capacity to solve the problem of electricity supply shortage (Aderoju et al. 2017).

\section{Literature review}

In Nigeria, constant electricity supply remains a problem, despite the huge capital investment in the sector. Lack of access to electric power supply has impeded development in Nigeria (Oke 2016). Organic wastes are materials that are considered not to have any use in terms of its objectives, invention, conversion or utilisation which one wishes to alienate. Wastes may be produced during the removal of raw substances, the utilisation of final merchandises, and other human undertakings (Muhammad et al. 2013). According to Ibrahim (2002), organic wastes are undesirable materials or materials made in the course of manufacture and utilisation of goods, especially those that are traceable by-products from plants and animals. It is beneficial for wastes with a high proportion of organic non-biodegradable sustenance with little humidity contents (Lovley 2008; Sharmina et al. 2012).

There are various types of wastes: domestic waste; domestic waste, industrial waste and demolition waste, there are also hazardous wastes such as industrial waste, agricultural wastes, explosives wastes, bio-medical wastes such as medical wastes and radioactive wastes among others (Kothari et al. 2010; Arshad et al. 2018).

Currently, electricity supply in Nigeria relied significantly on hydropower, and this has resulted in frequent outages of electricity due to underinvestment in other sources of energy (Oke 2013). The average calorific value of wastes in Nigeria was approximately $9.6 \mathrm{MJ} / \mathrm{KG}$ based on the waste energy facility about $3000 \mathrm{MW}$ of electricity could be produced from waste to complement the existing power sources in Nigeria. Therefore, there is the need for efficiencies in collection, transportation and management of wastes (Atta et al. 2016). Majority of these scholars failed to discuss exhaustively on the fundamentals of conversion of wastes to electricity. Still, it only adumbrated on others bases of renewable energy, for instance, solar, wind and nuclear energy, among others.

Also, according to Oniemola and Sanusi (2007), renewable energy benefits are more than its environmental and social impacts. The present study is focused on the need for enactment of the legal framework with the incentive for utilising renewable energy as substitute sources of energy to encourage investors in the sector. These are gaps in the literature that the study intends to address in the Nigerian power sector. According to Akhator et al. (2016) conversion of wastes to energy technology is still at infancy stage in
Nigeria's power sector compared to other countries where it has been utilised to generate heat and electricity in commercial quantity for the benefits of their citizens.

\section{Legal and regulatory framework on renewable energy}

The National Energy Policy, 2003, is to encourage renewable energy resources and to decentralise energy supply in the country to ensure that $75 \%$ of Nigerians have access to electricity (Oyedepo et al. 2018). The challenge of the policy is the lack of adequate sanctions that commensurate with current economic reality in the sector and weak enforcement by the statutory agencies in the sector (Olujobi et al. 2018). Also, the Electricity Power Sector Reform Act, 2005 is to promote investments in renewable energy sources and to promote public and private sector collaborations in the provision of electricity to the rural communities in Nigeria. However, the law tended not to have achieved its objectives due to weak enforcement and lack of adequate incentives for investments in renewable energy sources to serve as assurance or security to foreign investors of getting returns on their investments (Olujobi 2017; Olujobi and Oyewunmi 2017). This is arguably a systemic challenge that extends beyond operational and structural challenges that would require a comprehensive approach to effectively address (Ufua et al. 2018).

The Nigerian Electricity Regulatory Commission (NERC) was instituted by Electric Power Sector Reform (EPSR) Act, 2005 to create, promote, and conserve productive energy market formations for optimum utilisation of energy sources for electricity services. The Nigerian Renewable Electricity Policy, 2006 is to promote independent renewable electricity systems for the provision of electricity in communities not covered by the national electricity grid for the sustainability of the power sector. This prompted the need to promote investment in renewable energy sources through private and public partnerships to promote access to electricity in all nooks and crannies in Nigeria. However, despite legal enactments guiding the operations of the Nigeria power sector, the challenge of sufficient power generation and the guarantee for reliable power supply has remained critical that has called for continuous attention, which justifies the effort put in the current research (Olujobi 2020b).

\section{Current trends in the conversion of wastes to electricity}

Biomass energy sources such as organic waste materials from the community wastes from agricultural produce and residues, as well as forestry resources such as wood wastes, 
are available extensively in Nigeria for the production of biofuel (Ngumah et al. 2013a). Conversion of wastes into electricity is speculated to reduce the volume of greenhouse gases, displacement of the higher cost of energy sources and costs of managing and disposing of wastes (Zsigraiová et al. 2009).

Besides, municipal solid wastes need to be appropriately managed in order not to impair sustainable development as it has been discovered that power generation from wastes incineration contributes extensively to replenishing energy generated from fossil fuels and decrease emissions (Olujobi and Olusola-Olujobi 2019; Matthew et al. 2020; Ufua et al. 2020b). Unfortunately, high capital and operating costs, feedstock collection cost, and feedstock variability and availability have prevented widespread use (Ogwueleka 2009). While the paradigm is changing, the challenge remains to develop a technology that is efficient and reliable, which requires minimal operating labour and maintenance and feedstock flexibility, and produces valuable commodities, to moderate caloric gas that is suitable for process heating, steam generation, or combustion in a reciprocating engine or gas turbine for generating electricity (Ngumah et al. 2013a).

Researchers (e.g., Hossain et al. 2018) reckon that substantial amounts of agronomic scums are made yearly in Nigeria, and are not optimised due to lack of technology, among other reasons. Models of agronomic scum are the rice pod, which comprises $25 \%$ of rice by quantity (Hossain et al. 2018), other residues include sugarcane fibres, coconut pods and hulks, groundnut husks, cereal straw among other things (Oke 2016). Furthermore, animal wastes are bases of biomass energy with animal and poultry manures. In the past, these wastes were convalesced and offered as fertiliser on agronomic land. However, the enactment of stringent ecological rules on air and water effluence means that wastes management are inevitable, which offers encouragements for the conversion of wastes to energy. The best desirable technique for transforming wastes resources to practical usage is anaerobic digestion which offers biogas that can be utilised as fuel for domestic incineration devices, to produce power from micro gas turbines, charbroiled for catering and water boiling (Ufua et al. 2019; Oke 2016).

\section{Prospects of wastes to electricity in Nigerian power sector}

The necessity for the reduction of greenhouse gas emissions offers an incentive to utilise bioenergy. Biomass can function as a carbon sink and as an alternative to fossils fuels (Ojolo et al. 2012). Its task is to reduce $\mathrm{CO} 2$ in the exosphere it is acknowledged under the Kyoto Protocol Articles 3.3 and 3.4. Biomass guarantees emissions diminutions through replacement of fossil fuels and is not hampered by the capacity of controlled biomass carbon sinks (Oke 2016). The replacement may be concluded with substantial carbon appropriation in untidiness and lands, varying on land-use transformations. The quantities of carbon replacement and appropriation will hinge on the plant type and other connected regulatory customs, plus soil categories.

Following the Kyoto Protocol, the objective is a decline of $8 \%$ of greenhouse gas emissions. Biomass could aid to avoid $\mathrm{CO} 2$ emissions by providing part of the energy demands in Nigeria, which would then be primarily met with fossil. Swelled application of biomass could make an extensive impact on the decrease in $\mathrm{CO} 2$ emissions and satisfy the Kyoto Protocol objectives (Chichilnisky and Hammond 2016). The technical preferences obtainable can be classified into two: Conventional steam cycle centred on plants and those centred on wood gasification knowledge (Food and Agriculture Organisation of the United Nations 2017). The conventional steam cycle power plants are centred on established know-how. The general plant productivity of the scheme is in the range of $18-22 \%$ dimensions accessible with this conventional know-how fluctuate between $10 \mathrm{~kW}$ and a few hundreds of Mega Watt (International Renewable Energy Agency 2017). It offers energy proficiency in the range of $30 \%$ or above for average-sized power plants, wood gasification-based technology utilised in biomass-based plants bearing in mind the technical practicability within Nigeria, plants functioning on conventional steam cycle machinery are uncovered to be suitable for biomass-based electricity generation system (Ufua et al. 2018).

There are efficiencies of generating plants functioning on conventional steam cycle based on ascertained technologies. The energy cost connected with biomass-based plants operating on traditional steam cycle technologies is similar to sizeable conventional gas turbine plants functioning on auto diesel. With the reduction in capital costs of biomass-based plants, the generally the prices are probable to reduce soonest (International Finance Corporation 2017). Consequently, biomass-based electricity production can become economical in Nigeria's electricity production system where fossil fuel-based production has a powerful module. As energy demands surges, fossil fuel stores decline, and coal having terrible pollution defects is not an option. Since biomass is mostly from plants, as long as fertile soil, sunshine, water, and carbon dioxide are available; biomass should sustain (Herrmann et al. 2018). To upsurge biomass influence as a renewable energy source, decrease greenhouse emission and enhanced green pastoral area growth. There are the needs for more excellent comprehension of the fiscal and ecological consequences of the diverse biofuel chains, their function in a progressing energy sector, and local growth. Biomass as a sustainable development tool is much easier to sustain in contrast to other sources of energy. As the bulk of the resources needed for the achievement of biomass are 
gotten from waste which cost little to acquire, biomass is easier to maintain (Aderoju et al. 2017). Currently, biomass has drawn extensive interest as an essential energy basis for electricity production, owing to its prospective as low cost, home-grown source of energy as well as owing to ecological values complementing biomass-based generation equipment (Aderoju et al. 2017).

The adoption of biomass as a sustainable energy tool will help in the achievement of the objective of the Kyoto Protocol by helping countries to reduce their emission levels produced from fossil fuels (Defra 2006). Nigerians are demanding a review of energy policy due to the anxieties over the outlook, security and variety of the energy resources which are utilised to produce power. Energy from wastes plants could play a restricted, but an enhanced role in generating electricity and offering heat to neighbourhoods (Atta et al. 2016). With fossil fuel prices intensifying in recent years, the desirability of energy from wastes module of the portfolio is expected to develop. A comprehensive review of energy policy is inevitable to drive proposals for waste plants to maximise the benefits of conversion of wastes to electricity in Nigeria (Oniemola and Sanusi 2007).

It will improve air quality, reduce emissions, and promote the conducive living acquisition of carbon credits and compliance with international climate agreements among others which are some of the gains that can be derived from the conversion of wastes to energy (The World Bank 2013). It is an ecological waste management mechanism that will end the habit of wastes collection and dumping in the site in an uncontrolled manner. This will extensively develop Nigeria's energy fusion and subsidise energy access for the future (Olujobi et al. 2020b) (Fig. 2).

\section{The prospective of biogas in Nigeria's power sector}

The country generates approximately 542.5 million tons of organic waste every year with the prospects of about 25.53 billion $\mathrm{m}^{3}$ (cubic metres) of biogas nearly 169,541.66 MW estimated at 1.01 trillion and 88.19 million tons of bio fertiliser in a year with the capacity to decrease ecological and public health anxieties, deforestation and greenhouse gas emissions (Ngumah et al. 2013a) (Table 1).

\section{Challenges of conversion of wastes to energy in Nigeria power sector}

Wastes disposal data in Nigeria are mainly unavailable or has not been published by environmental regulatory agencies due to lack of proper waste management controls and lack of political will and sincere commitment of the Federal Government to establish waste conversion to electricity facilities or plants (Imam et al. 2008). The value of renewable

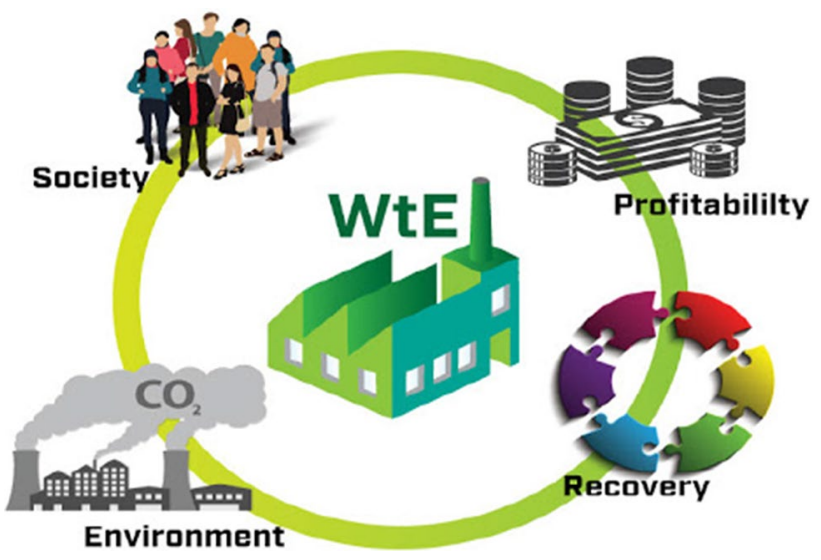

Fig. 2 Potentials of conversion of wastes to energy. Sources: Opportunities in the Waste-to-Energy Sector: https://www.google.com/ imgres?imgurl=http $\% 3 \mathrm{~A} \% 2 \mathrm{~F} \% 2 \mathrm{Ffdi}$-vietnam.com $\% 2$ fupload $\% 2 \mathrm{ftin}$ tuc\%2f1532400156wte.jpg\&imgrefurl=http\%3a\%2f\%2ffdi-vietn am.com\%2finvestment-opportunities\% 2 fvietnamopportunities-in-thewaste-to-energy-sector.html\&tbnid=iu9x0atun79ezm\&vet $=10 \mathrm{ce} 4$ qmyijawoxchmiqn7-v9_66wivaaaaab0aaaaaeai..i\&docid=a5lozcpagq vtjm \& $\mathrm{w}=763 \& \mathrm{~h}=570 \& \mathrm{itg}=1 \& \mathrm{q}=$ clearer $\% 20$ pictures $\% 20$ of $\% 20$ conversion $\% 20$ of $\% 20$ wastes $\% 20$ to $\% 20$ electricity $\% 20 \mathrm{in} \% 20 \mathrm{nig}$ eria\&hl=en\&ved=0ce4qmyijawoxchmiqn7-v9_66wivaaaaab0aaa aaeai. (Accessed September 21, 2020)

energy technology appears to be more than the traditional fossil fuel generation because it is a new technology which may require huge capital to start up (Shahrouz 2014). Also, the issue of land ownership structure in Nigeria under the Land Use Act 1978 confers ownership of land on the State Governors. They held the land in their states in trust for the people of that state as bioenergy plants would necessitate enormous land for farming of energy crops this may remain as an impediment to enormous scale farming if the consent of the Governors of the states is not sought which can impede the accessibility of primary substance for the bioenergy production by private investors and the Federal Government (Babatunde et al. 2012). Also, the animal manure for biofuel if left untreated in large quantities can have adverse effects on the environment. Feed-lots can produce wastes that are more concentrated than raw domestic sewage, and when such wastes are escapes into the water supply, the consequences can be disastrous (Ikpefan 2010) (Table 2).

\section{An overview of global policies on biomass energy utilisation}

Bioenergy potential in some countries is essential to learn from to foster policy for the development of Nigeria's power sector. The ecosystem and agronomy cross-cutting concerns are applicable in the meaning of harmonised act for bioenergy in numerous emerging countries; biomass is the only user-friendly and inexpensive basis of energy. In Africa, 
Table 1 Potentials of biogas in Nigeria's power sector. Source: Ngumah et al. (2013b)

\begin{tabular}{lllll}
\hline S. No. & Organic waste & $\begin{array}{l}\text { Amount of } \\
\text { units (millions) }\end{array}$ & $\begin{array}{l}\text { Total biomass generated } \\
\left(\text { million tons year }{ }^{-1}\right)\end{array}$ & $\begin{array}{l}\text { Estimated biogas } \\
\text { potential (billion }_{\mathrm{m}^{3} \text { year }^{-1} \text { ) }}\end{array}$ \\
\hline 1. & Urban solid waste & & 39.1 & 33,150 \\
2. & Crop remnants & & 83 & 117,000 \\
3. & Human faeces & 130 & 52 & 65,910 \\
4. & Slaughterhouse remnant & - & 83.3 & 103,350 \\
5. & Poultry droppings & 112.9 & 32.6 & 64,350 \\
6. & Pig excrement & 9.6 & 15.3 & 21,450 \\
7. & Sheep and goat excreta & 100.9 & 39.6 & 62,790 \\
8. & Cattle excreta & 21 & 197.6 & 142,350 \\
& Aggregate & 25.53 & 15.65 & 610,350 \\
\hline
\end{tabular}

Some organic wastes with enormous potentials in Nigeria are cattle faeces, sheep and goat dropping, pig excrement, poultry dropping, slaughterhouse leftover, human excrement, crop remainder, and urban solid wastes

Table 2 Power plants in Nigeria utilising renewable energy sources but not optimally. Source: Oluoti et al. (2014)

\begin{tabular}{lllllll}
\hline S/N & Power plants & Energy sources & Category & Capacity (MW) & Situation & $\begin{array}{l}\text { Date of } \\
\text { comple- } \\
\text { tion }\end{array}$ \\
\hline 1. & Mambilla Power Station & Hydroelectric & Reservoir & 3050 & Functioning but not optimally & 2018 \\
2. & Kiri Power Station & Hydroelectric & Reservoir & 100 & Functioning but not optimally & 2016 \\
3. & Zamfara Power Station & Hydroelectric & Reservoir & 35 & Functioning but not optimally & 2015 \\
4. & Kano Power Station & Hydroelectric & Reservoir & 100 & Work in progress \\
5. & Shiroro Power Station & Hydroelectric & Reservoir & 600 & Work in progress \\
6. & Jebba Power Station & Hydroelectric & Reservoir & 540 & Work in progress \\
7. & Kainji Power Station & Hydroelectric & Reservoir & 800 & Work in progress \\
\hline
\end{tabular}

biomass relates to half of the whole energy provision. Furthermore, to wood fuels, other biomass fuels such as forest and crop scums as well as animal wastes are usual bases of bioenergy in developing nations, where outdated types of machinery tend to be used in generating electricity (Thomsen 2014). Moreover, the quantity of biomass that is accessible in the form of scums, and the capacities for better quality and effectiveness in technology being currently useful several nations yet to designate lands for energy farmsteads (Chanakya and Malayil 2012). Incorporating biomass crops for energy targets with forestry and agronomic undertakings is alternative. In several areas, utilisation of biomass still needs to become ecological where traditional and contemporary machinery is useful (Ofoegbu and Emengini 2013).

Biomass is a vital energy source in several businesses, for instance, in the manufacture of ceramics, drinks, dehydration and processing of foods. The companies offer a necessity base and preliminary for accomplishing bioenergy projects in emerging nations with other proven profit-making undertakings (Food and Agriculture Organization of the United Nations 2017). These chances are often elapsed due to deficiency of technical know-how to enhance bioenergy systems, non-existence of supportive energy strategies, lack of supervisory capability and conventional energy development practice. The utilisation of solid biomass has had progressive growth in Organisation of Economic Cooperation and Development (OECD) nations, exhibiting yearly upsurge of $1.8 \%$ in contrast to $1.5 \%$ in non-OECD nations (Doornbosch and Steenblik 2007).

These countries were selected as a case study because they possess a structured legal regime on the conversion of organic wastes to electricity and with their requisite field experience on the conversion of wastes to electricity. Also, due to their relatively stable power supply generated via organic wastes in the country.

The central aims of the European Union in the energy sector, comprising energy utilisation in the transportation system, are to comply with the Kyoto Protocol goals to enhance energy efficiency security and mixture energy source, to improve efficiencies in the power sector and to create employment. A topical mandate on the endorsement of biofuels for transportation targets of substituting $2 \%$ of 
fossil fuels in transportation with biofuels (European Commission 1997).

The European Union renewable energy objective for biomass necessitates a substantial quantity of land and other sources. Agricultural land between 10 and 15\% has been devoted to non-food crops due to indicated growth in agricultural land, and countries are probable to record remarkable improvement ineffectiveness as a product of growing fiscal tension and contest (PricewaterhouseCoopers EU Services EESV's Consortium 2017). Thus, agriculturalists may appreciate the divergence to non-food energy crops. As fuel production continue to upsurge in Europe and healthier forest administration and the establishments of a new forest could add appreciably to more wood fuel. To intensify biomass support for renewable energy source, decrease greenhouse discharge and encourage rural ecological growth. There is the need for better comprehension of the fiscal and environmental consequences of various biofuel chains, their function in a progressing energy sector. The encouragement of bioenergy should be driven by stringent strategies directed at appropriating the ecological and countryside growth and advantages of bioenergy in a sustainable model (Olujobi and Olujobi 2020a, b).

The UK greenhouse gas emissions decline target is a $20 \%$ decrease, and when it comes to renewable energy generation, the objective is 10\% (National Strategy for Climate and Energy 2009). The government has introduced several policies to achieve this; for instance, about one-third of the renewable energy is anticipated to originate from biomass, which may necessitate up to 12,500 ha of energy crops for power production. The non-fossil fuel has aided the market for renewable energy predominantly winds power, but there is a little motivation for emerging renewable energy bases. The aim is to offer a fraction of their electricity from renewable energy bases (Alterner 2001). The green fuels issues, biodiesel, will entitle to 20\%-litre fuel incentive. Bioethanol is also eligible for 20 pence per litre incentive. The UK's government is in the course of aligning its target within the European biofuels mandate, and other devices may be necessary to aid in sustaining the objective. The UK's Department of Environment, Food and Rural Affairs earmarked $£ 30$ million for the establishment of energy crops and the formation of almost 6000 ha of energy crops (European Environment Agency 2002). There are also prospects for finance exhibition arrangements through finances sprung from the Climate Change Levy, but there is no distinct unified approach for the advancement of bioenergy mainstreaming long-term consideration. Such consideration should comprise analysis of ecological and socio-economic effects on the energy and agricultural sector in addition to regional advancement (Olujobi and Olusola-Olujobi 2019; Olujobi et al. 2020a).

In Italy, the government has endorsed a white paper on renewable energy and national strategies for the decline of greenhouse gases. The white paper specifies an objective of 8-10 Mtoe for vital energy from biomass 24 Mtoe for entirely renewable energy. This strategy is harmonised with biomass execution programme at the domestic level for renewable energy via biomass by the Ministry of Agriculture. Financial encouragements are encouraged on biodiesel for transportation which 300,000 are relieved from taxes for 3 years. Biodiesel for heating purposes is also exempted from tax with laudable objectives for biofuels energy demands.

Also, in Netherland, the country has adopted an utterly pre-emptive stand on energy and ecosystem concerns and set 5\% renewable target, rising from about $13 \%$ to about $70 \%$ yearly. The Dutch government is currently in the course of establishing objectives for the Netherlands within the European Union biofuels directive.

Likewise, in Sri Lanka, biomass accounts for $51 \%$ of energy supply in Sri Lanka (Wijayattunga et al. 2005). Biomass has drawn relevance as the primary energy basis for power production, owing to its prospective as a low cost, a home-grown supply of energy as well as due to ecological benefits complementary biomass-based generation technology. Besides this global advantage, there are local benefits such as reduction of soil erosion, restitution of degraded lands, and enrichment of local influences of fossil-fired power production. This has enhanced the stable power supply in these selected countries, which Nigeria can replicate to end power outage in the country.

\section{Limitations of the study}

There is dearth of accurate information on energy generation and consumption in Nigeria due to the confidentiality agreement executed by some regulatory agencies in the country with their business partners in the sector.

Also, some independent and private investors' are unwilling to make available the required data on energy consumption due to corruption and a lack of verifiable data.

\section{Conclusion}

The study has discussed the potentials of the transformation of wastes to energy in Nigeria and the need to explore alternative energy sources to reduce over-dependence on fossil fuel which is not environment friendly and exhaustible. Biomass has the prospect to become the primary basis of Nigeria's power sources for electricity production and other energy facilities. The extent to which bioenergy application will happen, and its percentage of realisation, will hinge on the supply, accessibility, financial and ecological supports, as well as policy, appraise stemming from climate change and enthusiasm to boost energy provisions self-reliance. 
Consequently, bioenergy encouragements must account for the eco-friendly features of the fuel chain from the production of the fuel to the energy service offered. A diversity of market-based devices can be utilised at several phases of the fuel chain to accelerate growth. In the case of energy crops, procedures need to be developed with greater collaboration among energy, agronomic and ecological strategies to inspire agrarians to produce biomass resources in an environmental modus.

However, biomass energy utilisation in Nigeria has been low, and in default of the impact of biomass, it will be challenging to sustain the carbon secretion decrease envisioned by the Kyoto Protocol.

It is suggested that the country should decentralise its energy sector and promote biomass utilisation to deliver electrical power supply, put stringent regulations in place for successful conversion of wastes to energy and enhance the reliability of the power sector.

\section{Recommendations}

The relevant legal framework should be enacted and enforced to encourage conversion of wastes to electricity considering over 14 million tonnes of combustible wastes in Nigeria with about 4.4 Terawatt-hour (TWh) of electricity could be generated annually from waste if the necessary financial supports and technologies are giving to the sector by the Federal Government. The National Environmental Standards and Regulations Enforcement Agency should wake up to its statutory responsibility of preserving and conserving the environment from pollutions. Likewise, the Nigerian Electricity Regulatory Commission should regulate the conversion of wastes to energy to benefit Nigerians by reducing air pollution and emissions of greenhouse gases. The introduction of mini-grids for power from scraps would end the problem of electricity outage in the pastoral communities that are not linked to the state-owned grid in the nation.

Financing power sector investment is one of the main problems facing the sector as finance from commercial banks is unavailable, or the interest rate is high (Akinyemi et al. 2019a, b; Okorie et al. 2020). Enhancing electricity provision in Nigeria and combating the hurdles to energy mix targets will require: tackling payment risk, financing energy investments in renewable energy sources in the power sector as well as overhauling of the pricing and tariff structure and energy market regulations.

There is a need for sensitisation of the public on the benefits of developing waste to an energy source for electricity in Nigeria. Waste to energy as the capacity to reduce landfill dumping and land designated as dumpsites in Nigeria. Such properties can be used for other purposes, while incineration of waste can produce desired electricity and reduce the quantum of wastes. Conversion of waste to electricity will reduce over-dependence on fossil fuels as energy sources. It can reduce gas emissions and pollution caused by the burning of fossil fuels. Conversion of wastes to energy is attainable in Nigeria's power sector, taking into consideration the country populace and enormous waste generated in the country which is not efficiently handled.

There is the need to develop stringent policies on energy efficiency to help in dealing with the hazard of waste production, to decrease greenhouse gas productions and to earn carbon credits to promote energy mix in Nigeria's power sector. Future research should consider towards coherent legal framework on renewable energy in Nigeria's power sector.

Acknowledgements The financial contribution of Covenant University, Nigeria, is greatly appreciated.

Authors' contributions OJ analysed and interpreted research on the legal framework in Nigeria; DE reworks the structure and design of the paper; MO analysed the theoretical framework; OM carries out the general editing of the manuscript.

Funding There is no funding for this research.

\section{Compliance with ethical standards}

Conflict of interest The authors declare that there is no conflict of interest.

Open Access This article is licensed under a Creative Commons Attribution 4.0 International License, which permits use, sharing, adaptation, distribution and reproduction in any medium or format, as long as you give appropriate credit to the original author(s) and the source, provide a link to the Creative Commons licence, and indicate if changes were made. The images or other third party material in this article are included in the article's Creative Commons licence, unless indicated otherwise in a credit line to the material. If material is not included in the article's Creative Commons licence and your intended use is not permitted by statutory regulation or exceeds the permitted use, you will need to obtain permission directly from the copyright holder. To view a copy of this licence, visit http://creativecommons.org/licenses/by/4.0/.

\section{References}

Aderoju OM, Dias GA, Echakraoui Z (2017) Assessment of renewable energy sources and municipal solid waste for sustainable power generation in Nigeria. In: World multidisciplinary earth sciences symposium, IOP conference, series: earth and environmental science, No. 7

Agboola OP (2011) Independent power producer (IPP) participation: solution to Nigeria power generation problem. In: Proceedings of the world congress on engineering, vol 3, pp 6-8

Akhator EP, Obanor AI, Ezemonye LI (2016) Electricity generation in Nigeria from municipal solid waste using the swedish wastes-toenergy model. J Sci Environ Manag 20(3):635-643 
Akinyemi O, Efobi U, Osabuohien E, Alege P (2019a) Regional integration and energy sustainability in Africa: exploring the challenges and prospects for ECOWAS. Afr Dev Rev 31(4):517-528. https://doi.org/10.1111/1467-8268.12406

Akinyemi O, Efobi U, Asongu S, Osabuohien E (2019b) Renewable energy, trade performance and the conditional role of finance and institutional capacity in sub-Sahara African Countries. Energy Policy 132:490-498. https://doi.org/10.1016/j.enpol.2019.06.012

Alterner (2001) The impact of renewable on employment and economic growth, EU report

Ankrah N, Manu E, Booth C (2015) Cradle to cradle implementation in business sites and the perspectives of tenant stakeholders. Energy Procedia 83:31-40. https://doi.org/10.1016/j.egypro.2015.12.193

Arshad M, Bano I, Khan N, Shahzad MI, Younus M, Abbas M, Iqbal M (2018) Electricity generation from biogas of poultry waste: an assessment of potential and feasibility in Pakistan. Renew Sustain Energy Rev 81:1241-1246

Atta AY, Aminu M, Yusuf N, Gano ZS, Ahmed OU, Fasanya OO (2016) Potentials of waste to energy in Nigeria. J Appl Sci Res 12(2): $1-6$

Babatunde SO, Opawole A, Akinsiku OE (2012) Critical success factors in public-private partnership (PPP) on infrastructure delivery in Nigeria. J Facil Manag

Bach V, Minkov N, Finkbeiner M (2018) Assessing the ability of the cradle to cradle Certifed ${ }^{\mathrm{TM}}$ products program to reliably determine the environmental performance of products. Sustainability 10(5): 1562

Chanakya HN, Malayil S (2012) Anaerobic digestion for bioenergy from agro-residues and other solid wastes-an overview of science, technology and sustainability. J Indian Inst Sci 92(1):111-143

Chichilnisky G, Hammond PJ (2016) The kyoto protocol and beyond: pareto improvements to policies that mitigate climate change (No. 287). Competitive Advantage in the Global Economy (CAGE), Coventry

Defra (2006) Municipal waste management statistics 2004/05. Defra, London

Doornbosch R, Steenblik R (2007) Biofuels: is the cure worse than the disease? research for the international institute for sustainable development's global subsidies initiative. https://www.oecd.org/ dac/environment-development/50559116.pdf. Accessed $25 \mathrm{Apr}$ 2020

Egbetokun S, Osabuohien E, Akinbobola T (2018) Feasible environmental Kuznets and institutional quality in North and Southern African Sub-regions. Int J Energy Econ Policy 8(1):104-115

Egbetokun S, Osabuohien E, Onanuga O, Akinbobola T, Gershon O, Okafor V (2020) Environmental pollution, economic growth and institutional quality: exploring the nexus in Nigeria. Manag Environ Qual 31(1):18-31. https://doi.org/10.1108/ MEQ-02-2019-0050

European Commission (1997) Energy for the future: renewable source of energy - white paper for a community strategy and action plan, Com final, Brussels (97), 599

European Environment Agency (2002) Energy and environment in the European Union. European Environment Agency, Copenhagen

Food and Agriculture Organization of the United Nations (2017), Egypt, Turkey and Ukraine sustainable bioenergy options from crop and livestock residues. http://www.fao.org/3/a-i8150e.pdf. Accessed 25 April 2020

Herrmann R, Jumbe C, Bruentrup M, Osabuohien E (2018) Competition between biofuel feedstock and food production: empirical evidence from sugarcane outgrower settings in Malawi. Biomass Bioenergy 114(July):100-111. https://doi.org/10.1016/j.biomb ioe.2017.09.002
Hossain SKS, Mathur L, Roy PK (2018) Rice husk/rice husk ash as an alternative source of silica in ceramics: a review. J Asian Ceram Soc 6(4):300

Ibrahim AM (2002) Introduction to environmental problems and management. Waadallah Environmental Consults (WADEC), Kano

Ikpefan OA (2010) Challenges of public-private partnerships in infrastructure financing in Nigeria. Niger Acc Horizon Univ Jos 4(1):61-76

Imam A, Mohammed B, Wilson DC, Cheeseman CR (2008) A solid waste management in Abuja, Nigeria. Waste Manag 28:468-472

International Finance Corporation (2017) Converting biomass to energy a guide for developers and investors. https://www.ifc. org/wps/wcm/connect/fb976e15-abb8-4ecf-8bf3-8551315dee 42/biomass_report_06+2017.pdf?mod=ajperes\&cvid=lphgoan. Accessed 17 May 2020

International Renewable Energy Agency (2017), Renewable power generation costs in 2017 (2018), Renewable power generation costs in 2017, Abu Dhabi

Jiang C, Ma J, Bonaccorso AD, Irvine JT (2012) Demonstration of high power, direct conversion of waste-derived carbon in a hybrid direct carbon fuel cell. Energy Environ Sci 5(5):6973-6980

Kopnina H (2018) Circular economy and cradle to cradle in educational practice. J Integr Environ Sci 15:119-134

Kothari R, Tyagi VV, Pathak A (2010) Waste-to-energy: a way from renewable energy sources to sustainable development. Renew Sustain Energy Rev 14(9):3164-3170

Li H, Yueling LIU, Jing Q (2020) U.S. Patent Application No. $16 / 736,829$

Lovley DR (2008) The microbe electric: conversion of organic matter to electricity. Curr Opin Biotechnol 19(6):564-571

Matthew OA, Ufua DE, Osabohien R, Olawande T, Edafe OD (2020) Addressing unemployment challenge through micro and small enterprises (MSEs): evidence from Nigeria. Probl Perspect Manag 18(2):79-89. https://doi.org/10.21511/ppm.18(2).2020.08

McDonough W, Braungart M (2002) Cradle to cradle: remaking the way we make things. North Point Press, New York

Minkov N, Bach V, Finkbeiner M (2018) Characterisation of the cradle to cradle certifed ${ }^{\mathrm{TM}}$ products program in the context of ecolabels and environmental declarations. Sustainability 10(3):738

Muhammad MU, Abubakar L, Musa A, Kamba AS (2013) Utilisation of wastes as an alternative energy source for sustainable development: a review. Chem Search J 4(1):57-61

National Strategy for Climate and Energy (2009) The United Kingdom Low Carbon Transition Plan. https://assets.publishing.servi ce.gov.uk/government/uploads/system/uploads/attachment_data/ file/228752/9780108508394.pdf. Accessed 25 Apr 2020

Ngumah C, Ogbulie J, Orji J, Amadi E (2013a) Potential of organic waste for biogas and bio-fertilizer production in Nigeria. Environ Res Eng Manag 1(63):60

Ngumah C, Ogbulie J, Orji J, Amadi E (2013b) Biogas potential of organic waste in Nigeria. J Urban Environ Eng 7(1):113

Ofoegbu GN, Emengini SE (2013) Recovery of cost of electricity supply in the Nigerian Power Sector. Res J Financ Acc 4:17

Ogwueleka T (2009) Municipal solid waste characteristics and management in Nigeria, pp 173-180

Ojolo SJ, Orisaleye JI, Ismail SO, Abolarin SM (2012) The technical potential of biomass energy in Nigeria. Ife J Technol 21(2):60-65

Oke Y (2013) Nigerian Electricity Law and Regulation. Law Lords Publication, Lagos, p 322

Oke Y (2016) Essays on Nigerian Electricity Law. Princeton and Associate Publishing Co. Ltd, Lagos, pp 93-113

Okeniyi JO, Anwan EU, Okeniyi ET (2012) Waste characterisation and recoverable energy potential using waste generated in a model community in Nigeria. J Environ Sci Technol 5(4):232-240 
Okorie U, Osabuohien E, Oaikhenan H (2020) Electricity consumption, public agricultural expenditure and output in Nigeria: a time series dynamic approach. Int J Energy Econ Policy 10(2):113-123. https ://doi.org/10.32479/ijeep.8436

Olaleye MA, Fagbenle RL (2013) Renewable municipal solid waste pathways for energy generation and sustainable development in the Nigerian context. Int J Energy Environ Eng 4:42

Olujobi OJ (2017) Legal framework for combating corruption in Nigeria-the upstream petroleum sector in perspective. J Adv Res Law Econ VIII(25):956-970

Olujobi OJ (2020b) Analysis of the legal framework governing gas flaring in Nigeria's upstream petroleum sector and the need for overhauling. Soc Sci 9:132

Olujobi OJ, Olujobi T (2020a) Theories of corruption: public choiceextractive theory as alternative for combating corruption in Nigeria's upstream petroleum sector. Int J Environ Sustain Green Technol (IJEST) 11(2):12

Olujobi OJ, Olujobi OM (2020b) Comparative appraisal of anti-corruption laws: lessons Nigeria can learn from Norway, United Kingdom and United States' anti-corruption strategies. Int J Manag 11:338-347

Olujobi OJ, Olusola-Olujobi T (2019) The appraisal of legal framework regulating gas flaring in Nigeria's upstream petroleum sector: how efficient? Int J Adv Res Eng Technol 10(3):234-250

Olujobi OJ, Oyewunmi OA (2017) Annulment of oil licences in Nigeria's upstream petroleum sector: a legal critique of the costs and benefits. Int J Energy Econ Policy 7(3):364-369

Olujobi OJ, Oyewunmi OA, Oyewunmi AE (2018) Oil spillage in Nigeria's upstream petroleum sector: beyond the legal frameworks. Int J Energy Econ Policy 8(1):220-226

Olujobi OJ, Olujobi OM, Ufua DE (2020a) The legal regime on renewable energy as alternative sources of energy in Nigeria's power sector: the impacts and the potentials. Acad Strateg Manag J 19(3):1-19

Olujobi OJ, Ufua DE, Olujobi OM (2020b) Renegotiation and stabilisation clauses in Nigeria's upstream petroleum industry's contracts: the issues and the options. Int J Innov Creat Change 14(2)

Oluoti K, Megwai G, Pettersson A, Richards T (2014) Nigerian wood waste: a dependable and renewable fuel option for power production. World J Eng Technol 2:234-248

Oniemola P, Sanusi G (2007) The Nigerian bio-fuel policy and incentives, a need to follow the Brazilian pathway. www.igee.org/en/ publication/newsletter. Accessed 18 Aug 2019

Onyekwena C, Ishaku J, Akanonu PC (2017) Electrification in Nigeria: challenges and way forward, Centre for the Study of the Economies of Africa (CSEA) Abuja, Nigeria. http://cseaafrica.org/wpcontent/uploads/2019/09/csea-electricity-project-nigeria-draft -report.pdf. Accessed 23 Apr 2020

Oyedepo SO (2012) Energy and sustainable development in Nigeria: the way forward. Energy Sustain Soc 2:15

Oyedepo SO, Babalola OP, Nwanya SC, Kilanko O, Leramo RO, Aworinde AK, Adekeye T, Oyebanji JA, Abidakun OA,
Agberegha OL (2018) Towards a sustainable electricity supply in Nigeria: the role of decentralised renewable energy system. Eur J Sustain Dev Res 2(4):40

Oyewunmi OA, Olujobi OJ (2016) Transparency in Nigeria's oil and gas industry: is policy re-engineering the way out? Int J Energy Econ Policy 5(4):630-636

PricewaterhouseCoopers EU Services EESV's Consortium (2017) Sustainable and optimal use of biomass for energy in the EU beyond 2020, Annexes of the Final Report. https://ec.europa.eu/energy/ sites/ener/files/documents/biosustain_annexes_final.pdf. Accessed 25 Apr 2020

Seddon J (2008) Systems thinking in the public sector. Triarchy Press, Charmouth

Shahrouz A (2014) A review of renewable energy supply and energy efficiency technologies. IZA Discussion Paper No. 8145, available at Shahrouz Abolhosseini. 17 May 2020

Sharmina B, Rasul MG, Delwar A (2012) An investigation on thermochemical conversions of solid wastes for energy recovery. World Acad Sci Eng Technol 6(2):624-630

The World Bank (2013) Low-carbon development opportunities for Nigeria. http://documents.worldbank.org/curated/en/2907514681 45147306/pdf/Low-carbon-development-opportunities-for-Niger ia.pdf. Accessed 17 May 2020

Thomsen ST (2014) Bioenergy in Ghana-Biogas and Ethanol from agricultural residues. $\mathrm{PhD}$ thesis, submitted at Center for Bioprocess Engineering (BIOENG), Department of Chemical and Biochemical Engineering Technical University of Denmark. file:///c:/users/hp/downloads/phdthesis_bioenergyinghanabiogasandethanolfromagriculturalresidues_sunetjalfethomsen_2014_978-87-93054-28-8.pdf. Accessed 17 May 2020

Ufua DE, Papadopoulos T, Midgley G (2018) Systemic lean intervention: enhancing lean with community operational research. Eur J Oper Res 268(3):1134-1148

Ufua DE, Olokundun AM, Ogbari ME, Atolagbe TM (2019) Achieving zero waste operation in a private organisation through extended stakeholders consultation: a case in the Niger Delta Region, Nigeria. Int J Mech Eng Technol (IJMET) 10(2):155-168

Ufua DE, Olujobi OJ, Ogbari ME, Moses CL, Edafe OD (2020a) Effects of the legal system on the operations of small and medium enterprises (SMEs) in Nigeria: a conceptual review. Palgrave Commun 7:94

Ufua DE, Salau OP, Dada JA, Adeyeye MO (2020b) Application of systems approach to achieving a cleaner and sustainable environment: a study of waste dumping issue on Idiroko Road, Ota, Ogun State, Nigeria. Int J Environ Sci Technol 1-10

Wijayattunga P, Daranagama U, Ariyadasa KP (2005) Techno-economic feasibility of biomass-based electricity generation in Sri Lanka. In: Silveira S (ed) Bioenergy—realising the potential. Elsevier, London, p 141

Zsigraiová Z, Tavares G, Semiao V, de Graça Carvalho M (2009) Integrated waste-to-energy conversion and waste transportation within island communities. Energy 34(5):623-635 